Article

\title{
Surface Enhanced Raman Spectroscopy Detection of Sodium Thiocyanate in Milk Based on the Aggregation of Ag Nanoparticles
}

\author{
Yanting Feng ${ }^{1}$, Rijian Mo ${ }^{1}$, Ling Wang ${ }^{1, *}$, Chunxia Zhou ${ }^{1,2}$, Pengzhi Hong ${ }^{1,2}$ and \\ Chengyong $\mathrm{Li}^{2,3,4, * \mathbb{D}}$ \\ 1 College of Food Science and Technology, Guangdong Ocean University, Zhanjiang 524088, China; \\ yanting_feng@163.com (Y.F.); rijian_mo@163.com (R.M.); chunxia.zhou@163.com (C.Z.); \\ hongpengzhi@126.com (P.H.) \\ 2 Shenzhen Institute of Guangdong Ocean University, Shenzhen 518108, China \\ 3 School of Chemistry and Environment, Guangdong Ocean University, Zhanjiang 524088, China \\ 4 Coastal Ecology Engineering Technology Research Center of Zhanjiang City, Guangdong Ocean University, \\ Zhanjiang 524088, China \\ * Correspondence: w16509@163.com (L.W.); cyli_ocean@163.com (C.L.); Tel.: +86-759-238-3636 (C.L.)
}

Received: 26 January 2019; Accepted: 12 March 2019; Published: 19 March 2019

\begin{abstract}
A method is developed for detecting the concentration of sodium thiocyanate $(\mathrm{NaSCN})$ in milk based on surface-enhanced Raman scattering (SERS) technology. A trichloroacetic acid solution can be used to enhance the SERS signal because of its function in promoting the aggregation of Ag nanoparticles (Ag NPs). Meanwhile, the protein in milk would be precipitated as trichloroacetic acid added and the interference from protein could be reduced during the detection. In this work, the enhancement factor $(\mathrm{EF})$ is $7.56 \times 10^{5}$ for sodium thiocyanate in water and the limit of detection (LOD) is $0.002 \mathrm{mg} / \mathrm{L}$. Meanwhile, this method can be used to detect the concentration of sodium thiocyanate in milk. Results show that SERS intensity increased as the concentration of sodium thiocyanate increase from 10 to $100 \mathrm{mg} / \mathrm{L}$. The linear correlation coefficient is $\mathrm{R}^{2}=0.998$ and the detection limit is $0.04 \mathrm{mg} / \mathrm{L}$. It is observed that the concentration of sodium thiocyanate does not exceed the standard in the three kinds of milk. The confirmed credibility of SERS detection is compared with conventional methods.
\end{abstract}

Keywords: surface-enhanced Raman scattering (SERS); milk; Sodium thiocyanate (NaSCN)

\section{Introduction}

Sodium thiocyanate (NaSCN) is a chemical used in medicine, printing and dyeing, chemistry, etc. [1-5]. To activate milk's advanced antibacterial system, the addition of trace amounts of NaSCN is the key [6]. NaSCN has a good natural antibacterial effect and low price, so the excessive addition of sodium thiocyanate still exists [7]. If excessive amounts of sodium thiocyanate are added to the milk, it will be harmful to the human body [6-10]. Therefore, the detection of NaSCN is of great importance.

To detect thiocyanate in milk, various methods have been reported including spectrophotometric, high-performance liquid chromatography (HPLC), etc. [11-16]. Although these methods have the advantages of high accuracy and sensitivity, they require expensive instruments and professional technicians, and they are subjected to complicated pretreatment long time consumption. Thus, it is urgent to develop a new method of rapidly detection NaSCN in milk.

Surface-enhanced Raman scattering (SERS) is one of the most popular tools for biosensor and chemical analysis [17-21]. It enables ultrasensitive detection technology to prove the ability to identify trace molecules and can be applied to the detection of toxins in food [22-27]. The matrix plays a vital 
role in SERS detection. Wu et al. [28] used a core-satellite substrate to detect melamine and NaSCN in milk and the limit of detection was $5.8 \mu \mathrm{g} / \mathrm{L}$. The SERS matrix was fabricated via immobilized Au nanoparticles (AuNPs) on polymer beads to form core-satellite nanostructures and the process was complicated. Zhang et al. [12] developed a method to detect NaSCN content in milk based on agarose SERS microchips and the limit of detection was $0.5 \mathrm{mg} / \mathrm{L}$. However, the microchip was needed and expensive equipment was required in the experiment. Ag NPs is a commonly used SERS active substrate. Some research has shown that the addition of substances such as salts and acids into Ag NPs would lead to the aggregation of nanoparticles, thereby generating a rich SERS hot spot and enhancing the Raman signal [13].

In this work, a method is developed for detecting the concentration of NaSCN in milk based on SERS method. Trichloroacetic acid is added to promote the precipitation of protein and the aggregation of Ag NPs. As a consequence, the Raman signal is enhanced and the interference from protein is reduced. The proposed method has been used in the detection of sodium thiocyanate for three kinds of milk in the supermarket.

\section{Materials and Methods}

\subsection{Reagents and Materials}

Silver nitrate $\left(\mathrm{AgNO}_{3}\right)$ was bought from Beijing Huawei Ruike Chemical Co., Ltd. (Beijing, China). Sodium citrate $\left(\mathrm{Na}_{3} \mathrm{C}_{6} \mathrm{H}_{5} \mathrm{O}_{7} \cdot 2 \mathrm{H}_{2} \mathrm{O}\right)$, sodium thiocyanate $(\mathrm{NaSCN})$ and trichloroacetic acid $\left(\mathrm{C}_{2} \mathrm{HCl}_{3} \mathrm{O}_{2}\right.$, TCA) were supplied by Shandong West Asia Chemical Industry Co., Ltd. (Shandong, China). Hydrochloric acid $(\mathrm{HCl})$ and nitric acid $\left(\mathrm{HNO}_{3}\right)$ were purchased from Lianjiang Ai Lianhua Reagent Co., Ltd. (Guangdong, China). All other reagents were analytically pure and used without purification.

Electronic analytical balance (A JJ124BC) purchased from Shenzhen Langpu Electronic Technology Co., Ltd. (Shenzhen, China). Aggregating heat constant temperature blender with magnetic force purchased (DF-101S) from Gongyi Honghua Instrument Equipment Industry \& Trade Co., Ltd. (Zhengzhou, China). UV-Visible absorption spectra (Hitachi, U-3900H) were obtained with a spectrometer. (Beijing, China). High-resolution transmission electron microscopy (JEOL, JEM-1400, Akishima City, Tokyo, Japan) was performed at $120 \mathrm{kV}$ to determine the sizes of Ag NPs. Spectral signals were acquired using a portable Raman spectrometer (Ocean Optics, SR-510 Pro, Beijing, China).

\subsection{Preparation of $A g N P s$}

A total of $100 \mathrm{~mL}$ of $0.18 \mathrm{~g} / \mathrm{L}$ silver nitrate was added to a clean round bottom flask. After the liquid heated to boiled, $2 \mathrm{~mL}$ of $1 \%$ sodium citrate solution was quickly added and reacted for $1 \mathrm{~h}$. When the solution eventually turned grayish yellow, the heating was stopped. After the silver colloid was cooled down, it was stored at $4{ }^{\circ} \mathrm{C}$ in the dark.

\subsection{Observation of Ag NPS}

To initially determine the particle size of Ag NPs, Ag NPs were diluted 10 times with ultrapure water, and then the maximum ultraviolet absorption wavelength of Ag NPs was measured using a UV-Visible spectrophotometer at a wavelength of 300-700 $\mathrm{nm}$.

Before characterization by transmission electron microscopy, $9 \mathrm{~mL}$ of $15 \%$ TCA was added to $1 \mathrm{~mL}$ of Ag NPs to generate aggregation of Ag NPs.

\subsection{Preparation of the Samples}

Preparation of NaSCN standard solution in milk: $30 \mu \mathrm{L}$ of different concentrations $(0,10,30$, $50,80,100 \mathrm{mg} / \mathrm{L}$ ) of NaSCN standard solution was added to $270 \mu \mathrm{L}$ of milk, then $900 \mu \mathrm{L}$ of $15 \%$ trichloroacetic acid was added. After that, the mixture was subjected to centrifugal treatment for $10 \mathrm{~min}$ $\left(4{ }^{\circ} \mathrm{C}, 12,000 \mathrm{rpm} / \mathrm{min}\right)$, with $120 \mu \mathrm{L}$ of supernatant and $10 \mu \mathrm{L}$ of Ag NPs mixed in the centrifuge tube. 
The detection of NaSCN in milk samples: $300 \mu \mathrm{L}$ of three kinds of milk was added into a $1.5 \mathrm{~mL}$ centrifuge tube containing $900 \mu \mathrm{L}$ of $15 \%$ trichloroacetic acid, respectively. Then samples were mixed thoroughly (for $1 \mathrm{~min}$ ), followed by centrifugation for $10 \mathrm{~min}\left(4^{\circ} \mathrm{C}, 12,000 \mathrm{r} / \mathrm{min}\right)$. A total of $120 \mu \mathrm{L}$ of supernatant and $10 \mu \mathrm{L}$ of Ag NPs were thoroughly mixed and let stand for 6 min before Raman detection.

\subsection{Detection of NaSCN with SERS}

In SERS measurement, the wavelength of excitation laser was $785 \mathrm{~nm}$ and the power was set to $350 \mathrm{~mW}$. The spectrum was collected from 170 to $3900 \mathrm{~cm}^{-1}$ with a spectral resolution of $4 \mathrm{~cm}^{-1}$. The probe working distance was $7.5 \mathrm{~mm}$ and the spot diameter was less than $2 \mathrm{~mm}$. In this experiment, SERS was measured at $30 \%$ power $(105 \mathrm{~mW})$ and a single $15 \mathrm{~s}$ accumulation. It was detected in the dark to minimize the signal from the fluorescent lights. Data acquisition and analysis were performed using the spectrometer's AccuRam software.

\subsection{Detection of NaSCN with UV-Visible Absorption}

A total of $15 \mathrm{~mL}$ milk and $10 \mathrm{~mL}$ TCA $(200 \mathrm{~g} / \mathrm{L})$ were added into a centrifuge tube and shocked vigorously. It was settled for $30 \mathrm{~min}$. After centrifugation (9000 rad/min, 3min), the supernatant was filtered. A total of $4 \mathrm{~mL}$ filtered solution was added to a $10 \mathrm{~mL}$ colorimetric tube, followed by addition of $2 \mathrm{~mL}$ ferric nitrate solution and reacted for $10 \mathrm{~min}$. Then it was measured using a UV-Visible spectrophotometer at a wavelength of $450 \mathrm{~nm}$.

\section{Results and Discussions}

\subsection{Characterization of $\mathrm{Ag} N \mathrm{NS}$}

The UV-Vis spectrum of the Ag NPs is shown in Figure 1a. The morphology, size and distribution of the Ag NPs could be characterized by the position and peak shape of the maximum absorption. There is an Ag NPs maximum ultraviolet absorption at $405.5 \mathrm{~nm}$, which corresponds to the Ag NPs diameter of about $55 \mathrm{~nm}$. It can be seen that the peak shape of the peak is narrow, indicating that the Ag NPs prepared by the method is mostly spherical and has a uniform particle size distribution. Most of Ag NPs present are as a monomer before the addition of coagulant (Figure 1b). The shape of Ag NPs is spherical. The particle size distribution is relatively uniform and the majority of the particle size distribution of Ag NPs is $55 \mathrm{~nm}$ (Figure 1c). The diameters of Ag NPs are almost identical. After the addition of the coagulant TCA, the potential balance of the colloid is destroyed, leading to the aggregation of Ag NPs. As can be observed in Figure 1d, the aggregated Ag NPs has a richer SERS hot spot, which can enhance the Raman signal of NaSCN. 

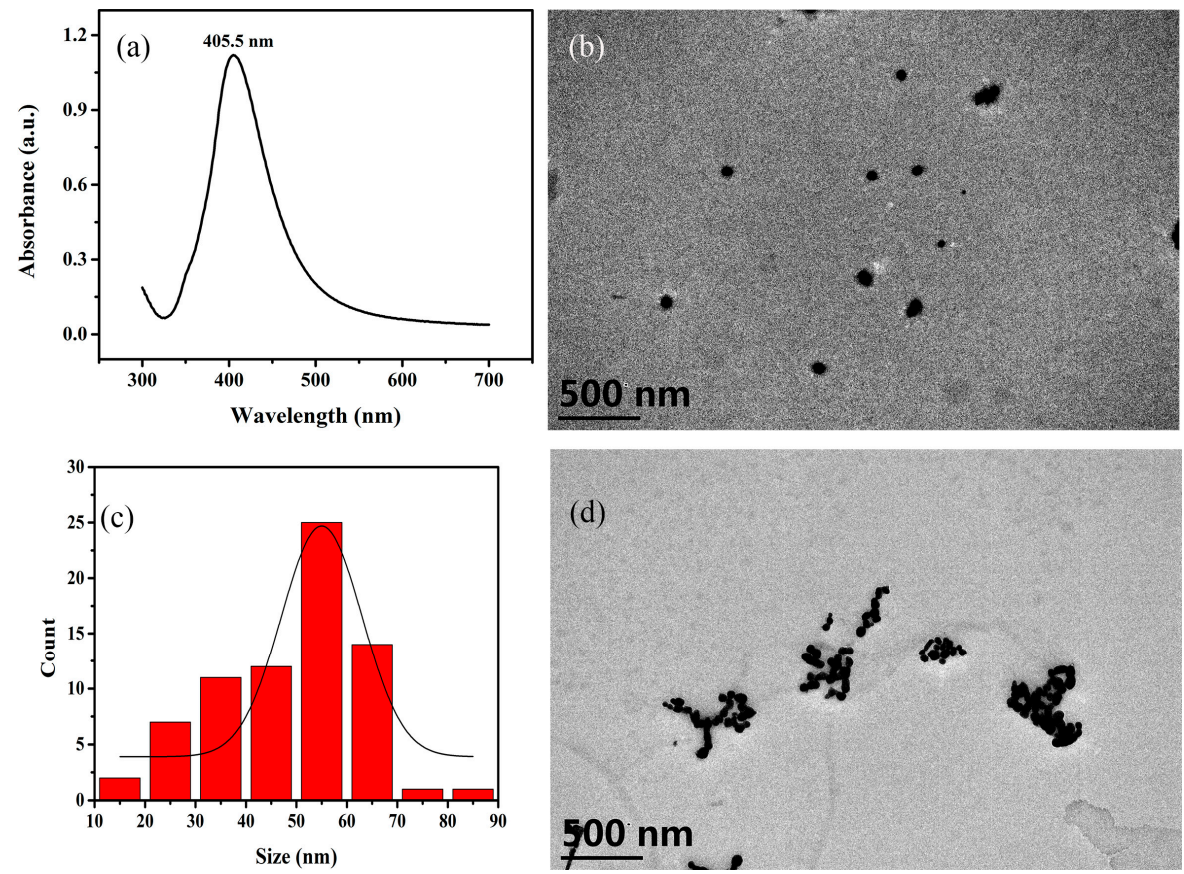

Figure 1. The characteristics of Ag NPs. (a) UV-Vis spectrum of Ag nanoparticles (NPs) as prepared. (b) Transmission electron microscope (TEM) image of Ag NPs as prepared. (c) Particle size distribution of Ag NPs (d) TEM image of Ag NPs after the addition of trichloroacetic acid (TCA).

\subsection{SERS Detection of NaSCN}

As shown in Figure 2a, there are two characteristic peaks of NaSCN powder at $753 \mathrm{~cm}^{-1}$ and $2075 \mathrm{~cm}^{-1}$, respectively. The absorption peak at $753 \mathrm{~cm}^{-1}$ is caused by the C-S bond stretching vibration. The other absorption peak at $2075 \mathrm{~cm}^{-1}$ is attributed to the antisymmetric stretching vibration of $-\mathrm{C} \equiv \mathrm{N}$ bond, which is chosen as the characteristic peak for identifying of NaSCN due to its high intensity [29]. In the experiment, the peak position of $\mathrm{SCN}^{-}$in the solution is shifted to $2126 \mathrm{~cm}^{-1}$ compared to the one in sodium thiocyanate powders $\left(2075 \mathrm{~cm}^{-1}\right)$. It has been reported that when thiocyanate ions are adsorbed on the surface of Ag NPs, the peak position will change due to the different adsorption modes of ions in solution [30]. When NaSCN is added, Ag NPs are aggregated (Figure 2b). The Raman signal is hardly found in $10^{4} \mathrm{mg} / \mathrm{L} \mathrm{NaSCN}$ even Ag NPs were added. After the addition of TCA to the above solution, an obvious Raman signal can be observed. This indicates that the aggregation of Ag NPs caused by the coagulant TCA has a good reinforcing effect on the Raman signal of NaSCN. There is a perfect gap between the condensed Ag NPs, which provide a mass of SERS hot spots. When the NaSCN molecule is adsorbed to the gap of the nanoparticles, the Raman signal of NaSCN would be greatly enhanced. In order to investigate whether the addition of TCA interferes with the SERS signal of NaSCN, the SERS spectrum of the mixed solution of TCA and Ag NPs was verified in the experiment. As depicted in Figure $2 b$, there is no obvious characteristic peak at a wave number of $1800 \sim 2500 \mathrm{~cm}^{-1}$ in pure TCA solution or a mixed solution of TCA and Ag NPs. Thus, they do not interfere with the Raman signal of NaSCN. 

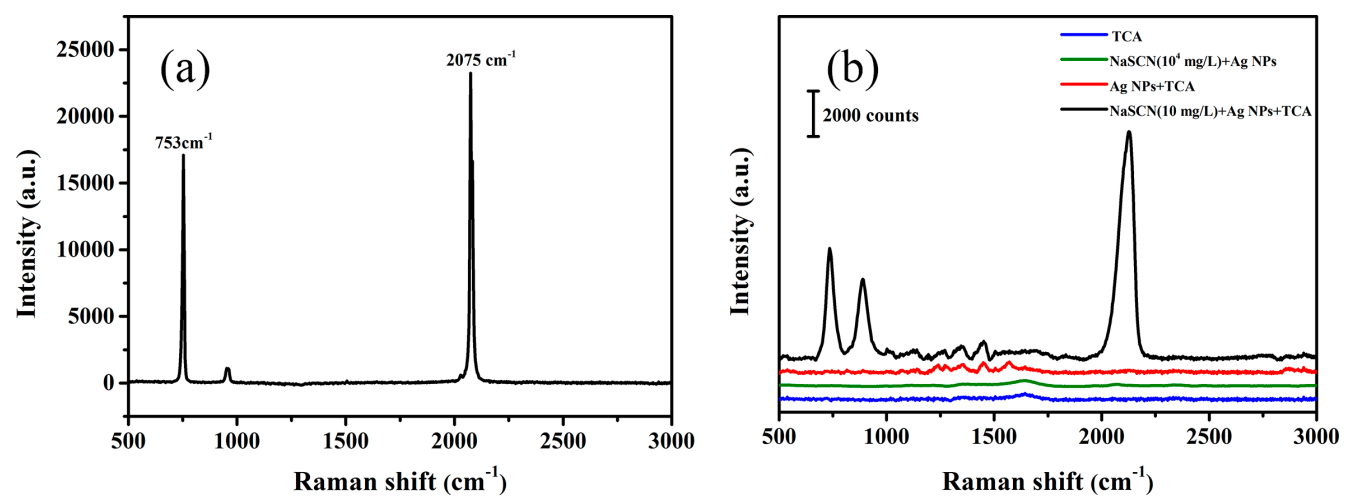

Figure 2. The Raman spectra of the samples. (a) NaSCN solid powders. (b) TCA, a mixed solution of TCA and Ag NPs, a mixed solution of NaSCN and Ag NPs, a mixed solution of NaSCN, TCA and Ag NPs.

When TCA is added into an Ag NPs solution, Ag NPs aggregate and SERS hot spots appear. The reaction time is important in this process. Figure 3 shows the relation curve between the SERS spectra and the reaction time. In the beginning, the hot spots appear and the intensity increases as TCA added. At about $6 \mathrm{~min}$, the intensity reaches the maximum. However, this reduces as the time increases gradually. Because a few of Ag NPs precipitate in the bottom, the SERS hot spots decrease slightly when the reaction time is too long.
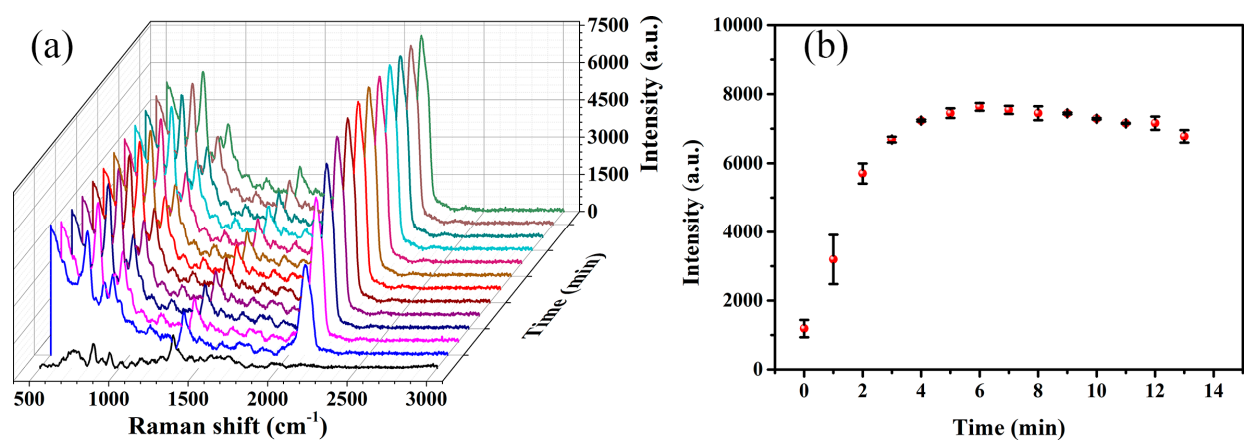

Figure 3. The relationship between surface-enhanced Raman scattering (SERS) spectra and the reaction time (repeated three times). (a) SERS spectra with different reaction times. (b) The relation curve between Raman spectra intensity $\left(2126 \mathrm{~cm}^{-1}\right)$ and the reaction time.

\subsection{SERS Detection of NaSCN in Aqueous Solution}

As shown in Figure 4a, a distinct characteristic peak at $2126 \mathrm{~cm}^{-1}$ in $0.1 \mathrm{mg} / \mathrm{L} \mathrm{NaSCN}$ solution is indicated. The intensity of Raman signal $\left(2126 \mathrm{~cm}^{-1}\right)$ rises with the increase in the NaSCN concentration. There has a linear range from $0.1 \mathrm{mg} / \mathrm{L}$ to $1 \mathrm{mg} / \mathrm{L}$ and LOD is $0.002 \mathrm{mg} / \mathrm{L}$ (Figure 4b). 

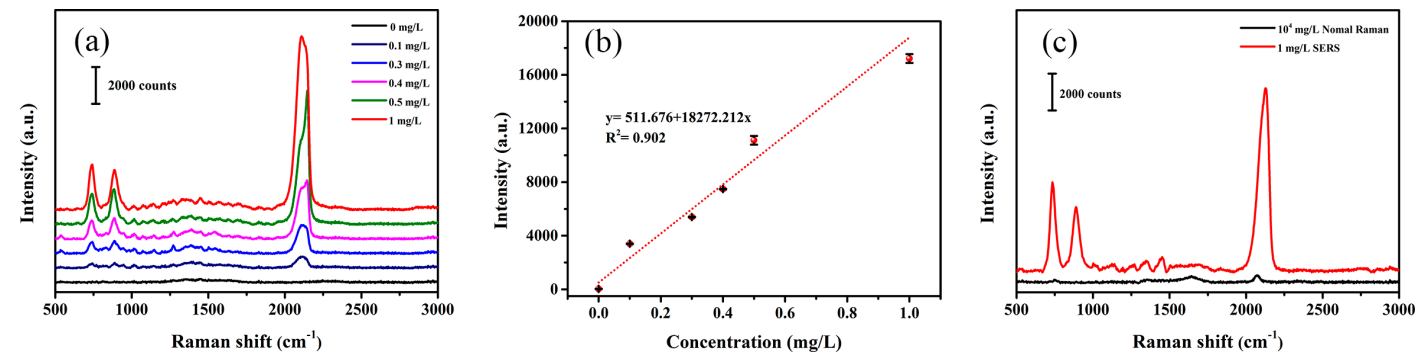

Figure 4. The SERS Detection of NaSCN in an aqueous solution (repeated three times). (a) The SERS spectra of NaSCN aqueous solution with different concentrations. (b) The relation curve between the intensity of SERS at $2126 \mathrm{~cm}^{-1}$ and the concentration of NaSCN. (c) The SERS spectrum of $1 \mathrm{mg} / \mathrm{L}$ NaSCN aqueous solution and conventional Raman spectrum of $10^{4} \mathrm{mg} / \mathrm{L} \mathrm{NaSCN}$ aqueous solution.

In order to calculate the enhancement factor of the Ag NPs, a conventional Raman signal with a concentration of $10^{4} \mathrm{mg} / \mathrm{L}$ aqueous NaSCN and a SERS Raman signal in a concentration of $1 \mathrm{mg} / \mathrm{L}$ were experimentally tested. The intensity of conventional Raman signal at $2126 \mathrm{~cm}^{-1}$ is 156 counts in $10^{4} \mathrm{mg} / \mathrm{L}$ NaSCN solution, while it can approach 11,794 counts in $1 \mathrm{mg} / \mathrm{L} \mathrm{NaSCN}$ solution. The following is the calculation formula for the enhancement factor (EF) of Ag NPs in aqueous solution:

$$
\mathrm{EF}=\frac{I_{S E R S}}{I_{N R}} \times \frac{C_{N R}}{C_{S E R S}}
$$

where $I_{S E R S}$ is the characteristic peak intensity of the surface-enhanced Raman spectrum; $I_{N R}$ is the characteristic peak intensity of the conventional Raman spectrum; $C_{S E R S}$ is the sample concentration of the surface-enhanced Raman spectrum; $C_{N R}$ is the sample concentration of the conventional Raman spectrum. Using the formula, the enhancement factor of Ag NPs is calculated to be $7.56 \times 10^{5}$.

\subsection{SERS Detection of NaSCN in Spiked Milk Samples}

In milk examples, there are mass of proteins, which hinder the detection of sodium thiocyanate. In this experiment, TCA is used to promote protein precipitation and gather Ag NPs simultaneously, without the requirement of additional processing during the measurement. As shown in Figure 5a, the concentrations of NaSCN were measured by SERS in the milk. The proteins contained in the milk would adsorb on the surface of the Ag NPs, which hinder the contact between thiocyanate and Ag NPs. Meanwhile, a portion of thiocyanate is absorbed by protein and thus precipitates upon the addition of TCA.
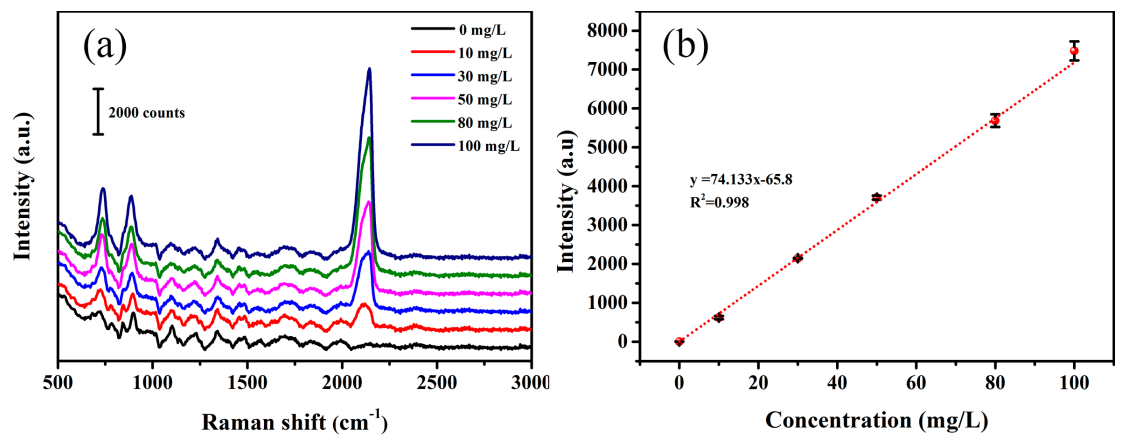

Figure 5. The SERS detection of NaSCN in the milk (repeated three times). (a) SERS spectra of the milk mixed with different concentrations of NaSCN. (b) The relation curve between the intensity of SERS at $2126 \mathrm{~cm}^{-1}$ and the concentration of NaSCN.

As seen in Figure $5 b$, the Raman signal of different concentrations $(0,10,30,50,80,100 \mathrm{mg} / \mathrm{L})$ of thiocyanate in milk was tested. With the range of $10-100 \mathrm{mg} / \mathrm{L}$, the Raman intensity of NaSCN follows the linear equation $I_{S E R S}=74.133 C_{N a S C N}-65.8$ with the linear correlation coefficient $R^{2}=0.998$. The 
calculated $\mathrm{LOD}$ value is $0.04 \mathrm{mg} / \mathrm{L}$ ( $\mathrm{LOD}=3 \mathrm{SD} / \mathrm{k}$, where $\mathrm{SD}$ and $\mathrm{k}$ are the standard deviation of the blank and the slope of the calibration graph respectively).

As showed in Figure 6, we tested three kinds of milk samples that are commonly found in the market, named sample A, sample B, sample C. There is no obvious peak at $2126 \mathrm{~cm}^{-1}$ for the three kinds of milk samples compared to that of the NaSCN spiked milk. Thus, it can be known that the concentration of $\mathrm{NaSCN}$ in the milk is less than $10 \mathrm{mg} / \mathrm{L}$.

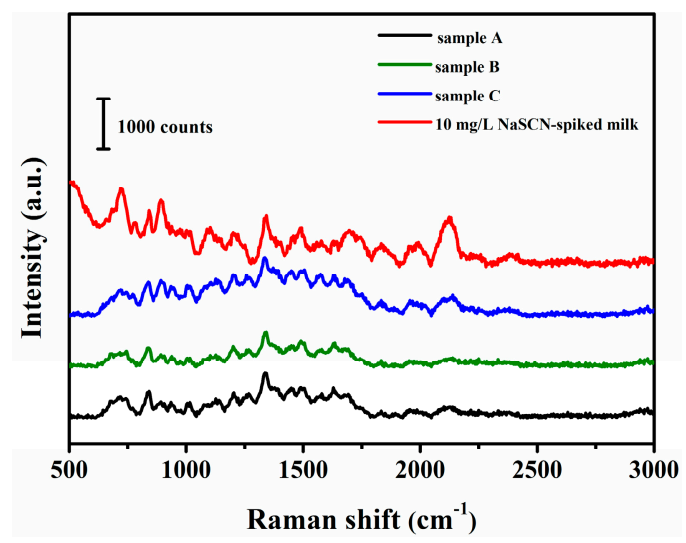

Figure 6. The SERS spectra of three kinds of commercial milk samples and spiked milk.

\subsection{Determination of NaSCN in Milk by UV-Visible Absorption Spectrometry}

In order to verify the accuracy of SERS detection, UV-visible absorption spectrometry was employed to measure the concentration of $\mathrm{NaSCN}$ in the milk. Figure 7 shows the standard curve measured by the UV-visible absorption spectrometry. There is an excellent linear relationship between the absorption and the concentration of $\operatorname{NaSCN}\left(\mathrm{R}^{2}=0.999\right)$, with a LOD of $0.069 \mathrm{mg} / \mathrm{L}$. As shown in Table 1 , the absorption is very weak at $450 \mathrm{~nm}$ for three milk samples. The concentration of NaSCN is $0.172,0.092,0.813 \mathrm{mg} / \mathrm{L}$ for sample A, B and C, respectively. Thus, they are much lower than $10 \mathrm{mg} / \mathrm{L}$, which is accordance with the results of SERS detection.
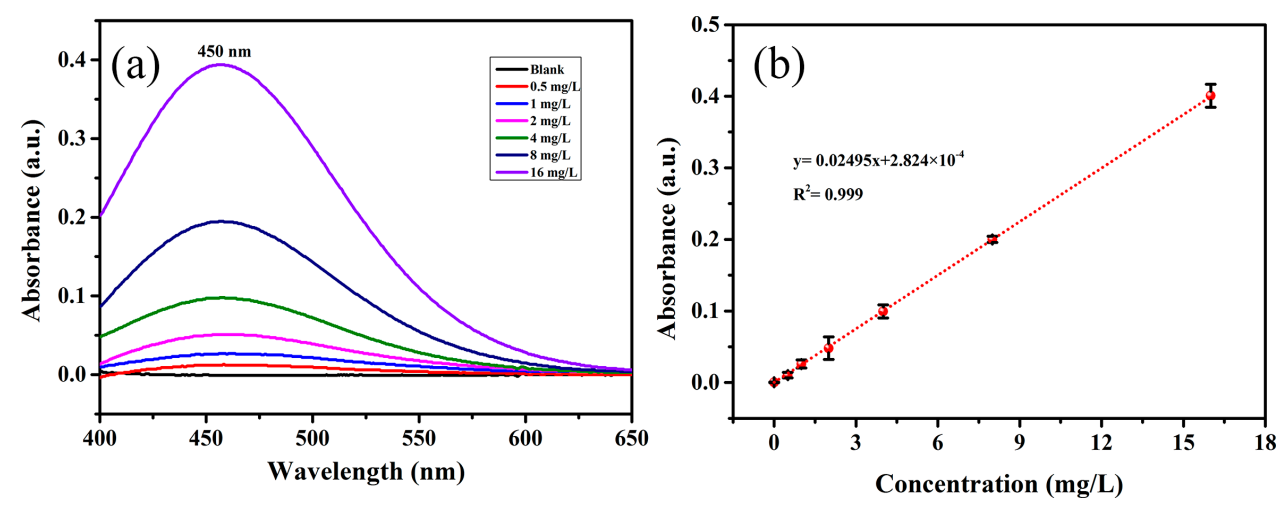

Figure 7. The detection of NaSCN in the milk via UV-visible absorption spectrometry (repeated three times). (a) UV-visible absorption of NaSCN with different concentrations in the milk. (b) The relation curve between the absorption at $450 \mathrm{~nm}$ and the concentration of NaSCN.

Table 1. The concentrations of NaSCN in three milk samples (UV-visible absorption spectrometry vs. surface-enhanced Raman scattering (SERS)) (repeated for three times).

\begin{tabular}{cccc}
\hline Mamples & $\begin{array}{c}\text { UV-Visible Absorption Spectrometry } \\
\text { Absorbance }(\boldsymbol{\lambda}=\mathbf{4 5 0} \mathbf{~ n m})\end{array}$ & $\begin{array}{c}\text { UV-Visible Absorption } \\
\text { Spectrometry }(\mathbf{m g} / \mathbf{L})\end{array}$ & $\begin{array}{c}\text { SERS Detection } \\
(\mathbf{m g} / \mathbf{L})\end{array}$ \\
\hline Sample A & $0.011 \pm 0.001$ & $<10$ & $<10$ \\
Sample B & $0.006 \pm 0.001$ & $<10$ & $<10$ \\
Sample C & $0.051 \pm 0.002$ & $<10$ & $<10$ \\
\hline
\end{tabular}




\section{Conclusions}

In this work, a method is developed for detecting the concentration of $\mathrm{NaSCN}$ in milk based on SERS method. Trichloroacetic acid is used to promote protein precipitation and gather Ag NPs simultaneously, without the requirement of additional processing during the measurement. The detection limit of NaSCN in water and milk is $0.002 \mathrm{mg} / \mathrm{L}$ and $0.04 \mathrm{mg} / \mathrm{L}$, respectively. The proposed method achieves good linearity $\left(\mathrm{R}^{2}=0.998\right)$ within the range of 10 to $100 \mathrm{mg} / \mathrm{L}$ of sodium thiocyanate in the spiked milk. In our verification test, the LOD of SERS $(0.04 \mathrm{mg} / \mathrm{L})$ was lower than the UV-visible absorption spectrometry $(0.069 \mathrm{mg} / \mathrm{L})$ which confirms the credibility of SERS when used for detection of NaSCN in milk. Therefore, it can be used to measure the concentration of sodium thiocyanate in milk quickly.

Author Contributions: Y.F. performed the experiments and wrote the paper; R.M. observed TEM images; L.W. measured Raman spectra; C.Z. analyzed the data; P.H. revised the paper; C.L. proposed the research topic and revised the paper.

Funding: This research is funded by the National Natural Science Foundation of China (21874029), Guangdong Yangfan Program (201635018), Guangdong Special Support Program (2017TQ04N706), Science and Technology Planning Project of Guangdong Province (2016A020210114), Technology Planning Project of Zhanjiang City (2018A02014, 2016C01002), Science and Technology Planning Project of Shenzhen City (JCYJ20170818111719650) and Industrial Development Special Funds of Dapeng New Area (KY20170209, KY20180202), Innovation and Development Project about Marine Economy Demonstration of Zhanjiang City (2017C8B1).

Conflicts of Interest: The authors declare no conflict of interest.

\section{References}

1. Kirman, C.R.; Belknap, A.M.; Webster, A.F.; Hays, S.M. Biomonitoring Equivalents for cyanide. Regul. Toxicol. Pharmacol. 2018, 97, 71-81. [CrossRef] [PubMed]

2. Bader, M.; Dunkel, A.; Wenning, M.; Kohler, B.; Medard, G.; del Castillo, E.; Gholami, A.; Kuster, B.; Scherer, S.; Hofmann, T. Dynamic Proteome Alteration and Functional Modulation of Human Saliva Induced by Dietary Chemosensory Stimuli. J. Agric. Food Chem. 2018, 66, 5621-5634. [CrossRef] [PubMed]

3. Hamblin, M.R.; Abrahamse, H. Inorganic Salts and Antimicrobial Photodynamic Therapy: Mechanistic Conundrums? Molecules 2018, 23, 3190. [CrossRef] [PubMed]

4. Xu, L.J.; Wang, H.Y.; Zheng, C.W.; Zhao, G. One-pot synthesis of (ethoxycarbonyl)difluoromethylthioethers from thiocyanate sodium and ethyl 2-(trimethylsilyl)-2,2-difluoroacetate (TMS-CF2CO2Et). Tetrahedron 2017, 73, 6057-6066. [CrossRef]

5. Abbes, C.; Mansouri, A.; Landoulsi, A. Synergistic Effect of the Lactoperoxidase System and Cinnamon Essential Oil on Total Flora and Salmonella Growth Inhibition in Raw Milk. J. Food Qual. 2018. [CrossRef]

6. Yong, L.; Wang, Y.B.N.; Yang, D.; Liu, Z.; Abernethy, G.; Li, J. Investigation of concentration of thiocyanate ion in raw cow's milk from China, New Zealand and the Netherlands. Food Chem. 2017, 215, 61-66. [CrossRef] [PubMed]

7. Leung, A.M.; Braverman, L.E.; He, X.M.; Schuller, K.E.; Roussilhes, A.; Jahreis, K.A.; Pearce, E.N. Environmental Perchlorate and Thiocyanate Exposures and Infant Serum Thyroid Function. Thyroid 2012, 22, 938-943. [CrossRef]

8. Dasgupta, P.K.; Kirk, A.B.; Dyke, J.V.; Ohira, S.I. Intake of Iodine and Perchlorate and Excretion in Human Milk. Environ. Sci. Technol. 2008, 42, 8115-8121. [CrossRef]

9. Zhang, T.; Wu, Q.; Sun, H.W.; Rao, J.; Kannan, K. Perchlorate and Iodide in Whole Blood Samples from Infants, Children, and Adults in Nanchang, China. Environ. Sci. Technol. 2010, 44, 6947-6953. [CrossRef]

10. Pearce, E.N.; Alexiou, M.; Koukkou, E.; Braverman, L.E.; He, X.M.; Ilias, I.; Alevizaki, M.; Markou, K.B. Perchlorate and thiocyanate exposure and thyroid function in first-trimester pregnant women from Greece. Clin. Endocrinol. 2012, 77, 471-474. [CrossRef]

11. Blount, B.C.; Valentin-Blasini, L. Analysis of perchlorate, thiocyanate, nitrate and iodide in human amniotic fluid using ion chromatography and electrospray tandem mass spectrometry. Anal. Chim. Acta 2006, 567, 87-93. [CrossRef] 
12. Zhang, Z.Y.; Liu, J.; Wang, H.Y. Microchip-Based Surface Enhanced Raman Spectroscopy for the Determination of Sodium Thiocyanate in Milk. Anal. Lett. 2015, 48, 1930-1940. [CrossRef]

13. Lin, X.; Hasi, W.L.J.; Lou, X.T.; Lin, S.; Yang, F.; Jia, B.S.; Cui, Y.; Ba, D.X.; Lin, D.Y.; Lu, Z.W. Rapid and simple detection of sodium thiocyanate in milk using surface-enhanced Raman spectroscopy based on silver aggregates. J. Raman Spectrosc. 2014, 45, 162-167. [CrossRef]

14. Yang, Q.Q.; Liang, F.H.; Wang, D.; Ma, P.Y.; Gao, D.J.; Han, J.Y.; Li, Y.L.; Yu, A.M.; Song, D.Q.; Wang, X.H. Simultaneous determination of thiocyanate ion and melamine in milk and milk powder using surface-enhanced Raman spectroscopy. Anal. Methods 2014, 6, 8388-8395. [CrossRef]

15. Tan, Z.; Lou, T.T.; Huang, Z.X.; Zong, J.; Xu, K.X.; Li, Q.F.; Chen, D. Single-Drop Raman Imaging Exposes the Trace Contaminants in Milk. J. Agric. Food Chem. 2017, 65, 6274-6281. [CrossRef]

16. Dong, W.L.; Xu, G. Spectrophotometic Determination of Trace Zinc in Milk Powder by Ethyl Rhodamine B. Asian J. Chem. 2014, 26, 5432-5434. [CrossRef]

17. Reguera, J.; Langer, J.; de Aberasturi, D.J.; Liz-Marzan, L.M. Anisotropic metal nanoparticles for surface enhanced Raman scattering. Chem. Soc. Rev. 2017, 46, 3866-3885. [CrossRef]

18. Ding, S.Y.; Yi, J.; Li, J.F.; Ren, B.; Wu, D.Y.; Panneerselvam, R.; Tian, Z.Q. Nanostructure-based plasmon-enhanced Raman spectroscopy for surface analysis of materials. Nat. Rev. Mater. 2016, 1. [CrossRef]

19. Cialla-May, D.; Zheng, X.S.; Weber, K.; Popp, J. Recent progress in surface-enhanced Raman spectroscopy for biological and biomedical applications: From cells to clinics. Chem. Soc. Rev. 2017, 46, 3945-3961. [CrossRef]

20. Wang, Z.Y.; Zong, S.F.; Wu, L.; Zhu, D.; Cui, Y.P. SERS-Activated Platforms for Immunoassay: Probes, Encoding Methods, and Applications. Chem. Rev. 2017, 117, 7910-7963. [CrossRef]

21. Amendola, V.; Pilot, R.; Frasconi, M.; Marago, O.M.; Iati, M.A. Surface plasmon resonance in gold nanoparticles: A review. J. Phys. Condens. Matter 2017, 29. [CrossRef]

22. Liu, B.; Zhou, P.; Liu, X.M.; Sun, X.; Li, H.; Lin, M.S. Detection of Pesticides in Fruits by Surface-Enhanced Raman Spectroscopy Coupled with Gold Nanostructures. Food Bioprocess Technol. 2013, 6, 710-718. [CrossRef]

23. Feng, J.Y.; Hu, Y.X.; Grant, E.; Lu, X.N. Determination of thiabendazole in orange juice using an MISPE-SERS chemosensor. Food Chem. 2018, 239, 816-822. [CrossRef]

24. Li, J.L.; Sun, D.W.; Pu, H.B.; Jayas, D.S. Determination of trace thiophanate-methyl and its metabolite carbendazim with teratogenic risk in red bell pepper (Capsicumannuum L.) by surface-enhanced Raman imaging technique. Food Chem. 2017, 218, 543-552. [CrossRef]

25. Zhang, Y.Y.; Yu, W.S.; Pei, L.; Lai, K.Q.; Rasco, B.A.; Huang, Y.Q. Rapid analysis of malachite green and leucomalachite green in fish muscles with surface-enhanced resonance Raman scattering. Food Chem. 2015, 169, 80-84. [CrossRef]

26. Luo, H.R.; Huang, Y.Q.; Lai, K.Q.; Rasco, B.A.; Fan, Y.X. Surface-enhanced Raman spectroscopy coupled with gold nanoparticles for rapid detection of phosmet and thiabendazole residues in apples. Food Control 2016, 68, 229-235. [CrossRef]

27. Zheng, J.K.; He, L.L. Surface-Enhanced Raman Spectroscopy for the Chemical Analysis of Food. Compr. Rev. Food Sci. Food Saf. 2014, 13, 317-328. [CrossRef]

28. Wu, L.-A.; Li, W.-E.; Lin, D.-Z.; Chen, Y.-F. Three-Dimensional SERS Substrates Formed with Plasmonic Core-Satellite Nanostructures. Sci. Rep. 2017, 7. [CrossRef]

29. Besemer, M.; Bloemenkamp, R.; Ariese, F.; van Manen, H.J. Identification of Multiple Water-Iodide Species in Concentrated NaI Solutions Based on the Raman Bending Vibration of Water. J. Phys. Chem. A 2016, 120, 709-714. [CrossRef]

30. Li, X.; Gewirth, A.A. Potential-dependent reorientation of thiocyanate on Au electrodes. J. Am. Chem. Soc. 2003, 125, 11674-11683. [CrossRef]

(C) 2019 by the authors. Licensee MDPI, Basel, Switzerland. This article is an open access article distributed under the terms and conditions of the Creative Commons Attribution (CC BY) license (http:/ / creativecommons.org/licenses/by/4.0/). 